\title{
A Practitioners Perspective on The Benefits of Open Innovation
}

\author{
Tim Stroh \\ tim@strohinternational.com | The Wilde Consulting Group, Melbourne, Australia \\ Letter from Industry
}

\begin{abstract}
The common approaches to innovation deployed by many corporations are ineffective and associated with a collection of well-defined risks including hype driven and biased decision making, risk aversion, and disruption. In contrast, open innovation programs reduce these same risks and deliver a variety of substantial benefits ranging from increased innovation speed, reduced costs, and increased probability of success.
\end{abstract}

Keywords. Open Innovation; Strategy; Innovative Performance; Innovation.

Cite paper as: Stroh, T., (2019). A Practitioners Perspective on The Benefits of Open Innovation - Letter from Industry, Journal of Innovation Management, www.open-jim.org, 7(2), 7-14. 


\section{The High Risk of Traditional Innovation Methods}

Large organizations are notoriously bad at innovating. In my experience, the vast majority respond to inconsistent or poor innovation outcomes by adopting methods used by others and thus perceived as rationally justifiable or safe even though results are uncertain. Problematically, these widely accepted methods do not appear to have changed the overall failure rate and, as such, are costly and unsustainable.

A superficial review of corporate innovation programs suggests many respond with innovation theatre. Organizations adopt and publicize initiatives that produce a market perception of innovativeness but deliver little in the way of actual innovative change and advancement. In Australia, for example, a quick review of media releases and news coverage over the last five years reveals of the largest banks, the top 10 insurance companies, and the big four consultancies nearly all have publicly adopted one or more of "Agile", "hack days", "fail fast fail cheap", an Innovation Lab, or a startup accelerator. Yet, none of these companies have introduced any substantial innovations in recent years. The "innovation" awards received and observable changes to their businesses are limited to incremental efficiency initiatives. These companies pursue the market benefits of being perceived as innovative including a positive impact on share price, superior ability to recruit high calibre new staff, and executive prestige but avoid the risks of large budget failures or customer attrition that can be caused by substantial but unappealing change. These so called "innovation" programs are largely limited to the adoption of current management fads. The vast majority remain focussed on modest incremental or low risk changes and, even when positive results are achieved, they are often short lived (Ahlback et al. 2018, Dahlström et al. 2018).

Another common response is to refocus on "core" customers and the "core" business. Organizations strive for product or service enhancements suggested primarily or exclusively by existing customers. While of value, this value is bounded and accompanied by several specific forms of risk. Adding new features or benefits based solely on traditional parameters such as requests from high-value customers leaves a company open to:

1. An unavoidable tendency toward incremental, status safe decisions (Stroh, 2018). This leaves an organization more susceptible to disruption (Christensen, 1997).

2. Poor or biased selection by executives. The so-called Hippo effect or overweighting of the highest paid person's opinion (Kohavi, et al., 2007; McAfee and Brynjolfsson, 2012). Even when tools or methods are used for feature selection, these methods have been shown to be subjective and the executive's interpretation of what should be done and ultimately what is fielded can often be unaligned with market demand (Stewart, 1992).

3. The changing nature of competition over time due to predictable and leverage-able hard trends in technology, demographics, etc. will change the nature of competition over time. No improvement to propeller fighter aircraft was ever going to make them competitive with jetpowered fighters. This wasn't disruption but an entirely predictable outcome of the progression of technology based on hard science and the known or calculated performance envelopes of the two technologies. 
4. Competitive activity that is comparable in nature but superior in design or execution. Pitting your weakness to an opponent's strength has always been and always will be recipe for disaster.

Finally, there are companies that manage the risk of innovation and market change by largely setting aside any internal drive to innovate. Instead, they plan to remain competitive by waiting to see what technologies, new products, and new startups succeed. They will then endeavour to buy the winners. While this approach appears to offer greater certainty, it is both very expensive and prone to a surprising level of failure. Acquisitions regularly don't work out. Buyers make their purchase a bit too early and the company that appeared to be the next big thing often proves to be more hype than substance. Others are destroyed by the attempts to integrate the new organization into the old or simply by poor due diligence, the acquired company was simply a poor choice and cannot perform as expected. Acquirers often make their decisions based on an extraordinary lack of front-line information or first-hand experience with the acquired company's staff, the interaction of line staff with management, their collective interaction with customers, or an objective picture of current and likely ongoing performance. The decision to purchase is often formed primarily around traditional methods of financial and business data analysis that focus on the rosy picture the seller paints and the buyer wants to hear. The same faulty decision processes that result in so many failed new products, organizational change initiatives, and attempts at innovation also result in a flawed consideration of selection criteria for new acquisitions. Purchases are then made while completely overlooking the role and impact of the target organisation's strategy, non-financial performance in context, and the predictable changes that are occurring within the context market.

Thankfully, there are superior alternatives. One of these is to establish an open innovation network.

\section{The Open Innovation Alternative}

One of these alternatives is the establishment of Open Innovation networks. "Open Innovation is the use of purposive inflows and outflows of knowledge to accelerate internal innovation, and expand the markets for external use of innovation, respectively" (Chesbrough, 2006).

Open innovation networks offer a variety of unique and substantial advantages over most traditional approaches to innovation. First and foremost, for most organizations there will generally be a variety of quick wins to be had simply by asking questions and looking widely outside their own industry. Surprising to many, the technical challenges faced when attempting to improve a product or services have often already been overcome in a different industry or discipline of research. Due to the limited nature of staff crossover between industries, the different terminology used across different arenas of activity, and the different ways in which problems are framed and described, awareness of shared challenges and solutions is limited (Dror, 2011; Kambourov and Manovskii, 2002, 2008; Leonard-Barton, 1995; Sternberg, 2002). Many successful innovations, from Nike Air trainers and the Black \& Decker Dust Buster to anti-lock brakes and silly string used for detecting boobytraps, are the product of a simple application of a piece of information, 
technology, product or service created for a niche need in one market to a similar or novel purpose in another.

Peter Borden has pointed out, "Most advances in science come when a person for one reason or another is forced to change fields." This sentiment is reinforced by Dorothy Leonard-Barton who says "Innovation occurs at the boundaries between mindsets, not within the provincial territory of one knowledge or skills base" (Leonard-Barton, 1995). Exposure to other industries and a diversity of perspectives, innovation challenges, and ways of thinking captured via an open network, the boundaries between industry specific mindsets, enhances the probability of success in spotting opportunities, team members being intellectually open to them, and objective consideration (Blomqvist et al., 2004; Tomlinson, 2010). This reality can yield quick results for those willing to open up about their challenges, take the time to explore different ways a question can be framed, and engage across industries and arenas of expertise (Asimov, 1959; Traitler, 2011). An open innovation network makes this process more probable, easier, and faster. Pursuing and sharing knowledge of your challenges and solutions in other industries is also a great basis to start the process of creating a network.

While it might seem counterintuitive, an open approach not limited to feedback from narrowly focussed customers or users also helps overcome several of the most significant hurdles to successful innovation. The primary barriers to successful innovation in most organizations are the social nature of human decision processes and the near-universal fear of loss of status associated with making decisions outside the accepted norms or an organization, industry, or discipline (Stroh, 2018). This social nature of decision making heavily biases decisions toward lower risk options such as incremental enhancements to existing products and services and against more substantial and valuable alternatives (Stroh, 2018). Embracing an open innovation network mandates interaction with a wider circle of executives and decision makers with different norms and perceptions of what might be worth trying. This changes the nature of social influence and the psychological risk profile of decisions. The norm is no longer determined exclusively by a single organization or a single executive team's perception of what is normal. Instead, the view of what is reasonable is expanded in proportion to the magnitude of the network and the depth of the interactions. Procter \& Gamble and Amazon's success across a variety of industries, markets and functions are excellent examples (Lafley, 2008).

The perception of tangible risk is also reduced where a network reveals similar successful solutions and decisions made by others for similar but different situations. If something doesn't work but was aligned with successful attempts in other industries, the broader community is unlikely to judge it as having been inappropriately risky and is more likely to judge it as a reasonable calculated risk. The widespread adoption of just in time manufacturing techniques and the evolution of a variety of lean production methodologies are good examples. The success of programs such as Google X (now the Moonshot Factory) which has pursued scientists, engineers, and managers from diverse industries who are in turn avidly sought after irrespective of the success of the projects they worked on is another example. The reduced risk of a loss of professional status resulting from unsuccessful innovative choices within a more open innovation community of professionals and peers will fundamentally change what decisions are considered and what projects are supported. Exposure to other industries, companies, and problems facilitates enhanced ob- 
jectivity and reduces the barriers or artificial boundaries inherent in entrenched paradigms and pre-existing more limited perspectives.

In addition, it is worth considering the growing importance of consumer offerings comprised of whole commercial ecosystems of interrelated products and services. I have conducted a brief survey of disrupted providers and markets. It suggests that susceptibility to disruption is reduced where organizations are part of a robust interdependent ecosystem of value to customers and increased where the value being transferred is the function of a single offering independent of others. Taxi's, video stores, and traditional mobile phones were easily disrupted because a superior offering that changed the criteria for selection could be easily substituted as a straight swap. It will be more difficult to disrupt smartphones, however, because they are part of an ecosystem offering. The value obtained by users from their smartphone is not simply a function of the hardware device but also the community of apps, app developers, and services accessible via the smartphone, its apps, and the smartphone's interaction with other devices. Banking, despite being ripe for disruption, is more resistant to disruption due to the ecosystem of players and value we obtain and rely upon including credit cards, access to merchant terminal networks, home loan broker networks, compliance with government legislation and thus insurance, and more.

Such networks and ecosystems can also facilitate value to an organization via improved staff engagement. Employees are the most important element of any business. Take care of them, and they'll take care of the customer, look out for risks, and constantly work to make things better. Placing artificial boundaries on your staff such that they can only see the world from one perspective is bad for them and fraught with risk for your organization. Building a learning organization, using the Prussian Staff concept to rotate people across positions, jobs, and areas of activity helps to expand horizons, reduces operational risks, builds capabilities, and fosters open mindsets to innovation. Doing so and actively assisting your best team members to move up by moving out of your organization and successfully into other organizations might seem counterintuitive. But the engagement value for those coming up through the ranks outweighs the costs in attrition. Further, the value of those staff when you poach them back after gaining a new and different perspective as well as their willingness to share via your expanded open innovation network is unprecedented. It is good for them and your organization. There is certainly research required on each of these topics to validate my observations as a practitioner. These have held true, however, across multiple businesses in different industries and of various sizes.

Finally, while the speed of technological advancement can diminish the apparent lifespan and thus return on investment from individual technologies, those that exist within and are fundamental to an ecosystem of value will have a greater lifespan. As the cost of major advances continues to rise, both optimizing ROI and reducing the risk of disruption become fundamental to success. The value of a focus on networks and ecosystems is further amplified by the increasing propensity of global markets to produce parallel invention or parallel discovery. From the simultaneously but independent development of the theory of evolution and the race to bring to market the first GUI to advanced AI systems for interpreting language that independently emerged on opposite sides of the planet, the modern world makes available similar information and inputs far more broadly than ever before. Just as intelligent people exposed to the same information will eventually 
reach the same or similar conclusions, so to the result of more people with the same cuttingedge information is more people independently coming up with similar new inventions. Most VC simply accept that if they are pitched something they love, it doesn't matter that they don't know of competitors. Those competitors are out there. This adds further value to both creating in context of an ecosystem and the value of speed that accompanies an open innovation network.

\section{Conclusion}

The benefits of open innovation are substantial and varied. For most organizations, open innovation should be part of the innovation mix and for many it should be part of the foundation of their innovation efforts. Open Innovation increases an organization's ability to see and capitalize on opportunities as well as deploy innovations that are more secure as elements of an ecosystem. While Open Innovation may not be suitable for every situation and the value of proprietary IP and traditional methods of IP protection must, of course, be considered, Open Innovation Networks make success more likely rather than less and rarely do so at the expense of an ability to protect IP either via traditional means or the development of an interdependent ecosystem of value. Facilitated cross-pollination, cooperative R\&D, and cooperative ecosystem development within broad but well considered boundaries has been shown to deliver benefits. Establishing open networks across industries will bring an invaluable diversity of ideas, problemsolving methods, and paradigms of thought that cannot be obtained effectively in any other way. It will also specifically deliver a host of tangible innovation benefits.

\section{References}

Ahlback, K., Comella-Dorda, S., \& Mahadevan, D. (2018, May 7) The drawbacks of agility. Accessed April 2019: https://www.mckinsey.com/business-functions/organization/our-insights/ the-organization-blog/the-drawbacks-of-agility

Asimov, Isaac. (1959) Isaac Asimov Asks, "How Do People Get New Ideas?" MIT Technology Review October 20, 2014

Blomqvist, K., Hara, V., Koivuniemi, J., \& Äijö, T. (2004) Towards networked R\&D management: the R\&D approach of Sonera Corporation as an example. RED Management, Volume 34, Issue 5, November 2004, Pages 591-603.

Chesbrough, H. (2006) Open innovation: A new paradigm for understanding industrial innovation. In: Chesbrough, H., Vanhaverbeke, W., West, J. (Eds). Open innovation: Researching a new paradigm, 1-12 (pp. 2). Oxford: Oxford University Press.

Christensen, C. M. (1997) The Innovator's Dilemma. New York: Harper Business.

Dahlström, P., Desmet, D, Singer M. (2018) The seven decisions that matter in a digital transformation: A CEO's guide to reinvention. Digital reinvention: Unlocking the 'how', 22. Accessed 


\section{April 2019:}

https://www.mckinsey.com/ /media/mckinsey/business\%20functions/mckinsey

\%20digital/our\%20insights/digital\%20reinvention\%20unlocking\%20the\%20how/

digital-reinvention_unlocking-the-how.ashx

Dror, I. (2011). The paradox of human expertise: why experts get it wrong. In: ed. Narinder Kapur. The Paradoxical Brain, (Ch 9). Cambridge: Cambridge University Press.

Kambourov, G., \& Manovskii I. (2002) Occupational Specificity of Human Capital, mimeo, The University of Western Ontario.

Kambourov, G., \& Manovskii, I. (2008) Rising occupational and industry mobility in the United States: 1968-1997. International Economic Review, 49(1):41-79.

Kambourov, G., \& Manovskii, I. (2009) Occupational specificity of human capital. International Economic Review, 50(1):63-115.

Kohavi, R., Henne, R.M., \& Sommerfield, D. (2007) Practical guide to controlled experiments on the web: listen to your customers not to the hippo, Proceedings of the 13th ACM SIGKDD international conference on Knowledge discovery and data mining, August 12-15, 2007, San Jose, California, USA

Lafley A. G. (2008) P\&G's innovation culture. Strategy+Business, Autumn. Accessed Jun 2009: http://www.strategy-business.com/media/file/enews-08-28-08.pdf.

Leonard-Barton, D. (1998) The Wellsprings of Knowledge: Building and Sustaining the Sources of Innovation (Pp. 64). Boston: Harvard Business School Press.

McAffee, A., \& Brynjolfsson, E. (2012) Big Data: The Management Revolution. Harvard Business Review Oct 2012.

Stanovich, K. (2009). What Intelligence Tests Miss. New Haven, CT: Yale University Press.

Sternberg, R.J. (Ed). (2002). Why Smart People can be so stupid. New Haven, CT: Yale University Press.

Stewart T. J. (1992) A critical survey on the status of multiple criteria decision making theory and practice, OMEGA International Journal of Management Science, Vol.20, No.5-6, 1992, 569586.

Stroh, T. (2018). A Deeper Truth: The new science of innovation, human choice, and societal scale behavior. New Jersey: Wilde Griffen Publishing Bookbaby.

Traitler H., Watzke H.J., \& Saguy I.S. (2011) Reinventing R\&D in an Open Innovation Ecosystem. Journal of Food Science, Volume76, Issue2, March 2011, Pages R62-R68

Tomlinson, P.R. (2010). Co-operative ties and innovation: some new evidence for UK manufacturing. Research Policy 39, 762-775. 


\section{Biographies}

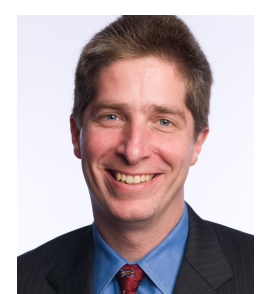

Tim Stroh. Tim Stroh is currently pursuing a Ph.D. in Management at the Royal Melbourne Institute of Technology (RMIT) in Melbourne, Australia. His research interests include sociobiology, neuroscience, motivation, innovation, and organizational structures and norms. From 1993 to 2019, he worked as a serial entrepreneur, senior executive, and consultant. In addition to pursuing his Ph.D. he is currently head of strategy and product for Art Processors (a member of the Moorilla group of companies), is a start-up mentor for the Spark Accelerator program at Deakin University, provides consulting services to large enterprise on strategy, innovation, building engaged organizations and deploying effective and ethical incentive programs. He is also a regular keynote speaker. His publications include A Deeper Truth: The new science of innovation, human choice and societal scale behavior (2018). Mr. Stroh has been awarded several patents, the 4th Annual Ethical Investor Sustainability Award for new products in 2006, StartupSmart's 2014 So You Think You Can Start-up pitching competition and his book has received a variety of awards and medals. He has also developed and launched hundreds of products across multiple industries and taken multiple start-ups from concept through to successful trade-sale exit.

\section{ISSN 2183-0606}

